\title{
Die - Charmages
}

ZA de Cocause, RD543

\section{Frédérique Thiercelin-Ferber}

\section{(2) OpenEdition}

\section{Journals}

Édition électronique

URL : http://journals.openedition.org/adlfi/14764

ISSN : 2114-0502

Éditeur

Ministère de la culture

Référence électronique

Frédérique Thiercelin-Ferber, «Die - Charmages », ADLFI. Archéologie de la France - Informations [En ligne], Rhône-Alpes, mis en ligne le 20 mai 2015, consulté le 03 mai 2019. URL : http:// journals.openedition.org/adlfi/14764

Ce document a été généré automatiquement le 3 mai 2019.

(C) Ministère de la Culture et de la Communication, CNRS 


\title{
Die - Charmages
}

\author{
ZA de Cocause, RD543
}

\section{Frédérique Thiercelin-Ferber}

Code INSEE de la commune : 26113

Lien Atlas (MCC) :

http://atlas.patrimoines.culture.fr/atlas/trunk/index.php?

ap_theme=DOM_2.01.02\&ap_bbox=5.314;44.711;5.461;44.792

1 L'intervention archéologique réalisée au lieu-dit ZA de Charmages-Cocause se situe à l'est de la commune de Die, sur une parcelle concernée par l'extension de la zone artisanale. Préalablement à la réalisation de ce projet, le SRA a décidé de procéder à un diagnostic archéologique afin de déterminer le potentiel archéologique du terrain. En ouvrant 7,5\% de la surface prescrite, ce diagnostic a révélé la présence de huit structures archéologiques : quatre fossés, deux fosses (dont une crémation antique) et deux tumuli de l'âge du Fer.

2 Faute de mobilier, les quatre fossés ne sont pas datables. En revanche, un vase retrouvé dans la crémation F52.1 permet de dater cette structure entre les dernières décennies du $\mathrm{II}^{\mathrm{e}} \mathrm{s}$. et la première moitié $\mathrm{du} \mathrm{III}^{\mathrm{e}} \mathrm{s}$. Une fenêtre ouverte autour du sondage 52 n'a révélé aucune crémation supplémentaire, laissant supposer que cette découverte est isolée.

3 Les deux tumuli n'ont été que partiellement ouverts. Le peu de mobilier récolté (un petit fragment de céramique et une perle en bronze) est attribuable à l'âge du Fer. Ces objets étaient associés à une inhumation placée au centre de l'un des deux monuments funéraires (F46.7). Cette sépulture n'a pas été fouillée.

4 Si l'on se réfère au recensement effectué par B. Dedet à propos des variations des pratiques funéraires protohistoriques dans le sud de la France (Dedet, 2004), aucune structure comparable n'est encore connue dans la Drôme. Les deux tumuli mis au jour à Die constituent donc une découverte exceptionnelle en moyenne vallée du Rhône. Des différences sont flagrantes entre les deux structures, et il est possible qu'elles ne soient pas strictement contemporaines. Des éléments de comparaison existent, permettant d'évoquer un rattachement chronologique pour ces deux ensembles. Ainsi, le 
tumulus 46.7 avec ses dalles disposées en pétale peut être rapproché du tumulus des Combes 1, daté du BFIIb, retrouvé sur la commune des Bondons en Lozère (Dedet, 2001), tandis que les appendices pierreux du tumulus F9.1 rappellent le tumulus $\mathrm{n}^{\circ} 1$ de la croix de Baptiste à Vèze dans le Cantal daté du Bronze A2, et ensuite réutilisé au Hallstatt C2, comme le montre le dépôt d'une inhumation adventice dotée d'une épée en fer (Delrieu et Milcent, 2006). Seule la fouille méticuleuse de ces structures du Diois pourrait permettre de les dater avec précision.

INDEX

Index géographique : Rhône-Alpes, Drôme (26), Die

Keywords : fosse, fossé, tumulus, céramique, crémation

operation Opération préventive de diagnostic (OPD), 2013 - n OA : 2211283

Index chronologique : âge du Fer

\section{AUTEURS}

\section{FRÉDÉRIQUE THIERCELIN-FERBER}

Inrap 